\title{
MEDICAL VS SURGICAL TREATMENT FOR SYMPTOMATIC ENLARGED INFERIOR TURBINATE: A COMPARATIVE STUDY
}

\author{
Habib-Ur-Rehman, Fazal-I-Wahid, Bakht Zada, Muhammad Javaid, Naseem Ul Haq \\ Medical Teaching Institute, Lady Reading Hospital, Peshawar Pakistan
}

\begin{abstract}
Objective: To determine the nasal patency after reducing the size of hypertrophied inferior turbinate with medication and surgery.

Study Design: Prospective comparative study.

Place and Duration of Study: Department of Ear, Nose, Throat, Head and Neck Surgery, Medical Teaching Institute, Lady Reading Hospital, Peshawar Pakistan, from Jan to Dec 2019.

Methodology: This study was conducted at the After-sample size calculation using an online sample size calculator (OpenEpi) and after obtaining informed consent patients were divided into two groups. Patients in group A were put on medicine only and in group B surgery was conducted to reduce the size of hypertrophied inferior turbinate. Data were analyzed using SPSS version 25 and $p<0.05$ was considered significant.

Results: This study comprised of total 86 patients, in the age range $15-55$ years with mean \pm SD age $33.47 \pm 9.57$ years. Males were $47(54.7 \%)$ and females were $39(45.3 \%)$ with male to female ratio of 1.2:1. In group A, males were $22(25.25 \%)$, females were $21(24.41 \%)$, while in group B males were $25(29.1 \%)$ and females were $18(20.3 \%)$. There was no statistically significant difference in nasal patency between the two groups before treatment $(p=0.59)$ and after 10 days of treatment $(p=0.69)$. However, at the end of one month, there was a statistically significant difference in nasal patency between the medically treated and surgically treated groups of patients $(p=0.023)$.
\end{abstract}

Conclusion: Surgical treatment is significantly effective than medical treatment alone.

Keywords: Hypertrophy, Inferior turbinate, Nasal obstruction, Outer displacement.

How to Cite This Article: Rehman H, Wahid F, Zada B, Javaid M, Haq NU. Medical vs Surgical Treatment for Symptomatic Enlarged Inferior Turbinate: A Comparative Study. Pak Armed Forces Med J 2021; 71 (Suppl-3): S487-490. D Doi:https://doi.org/10.51253/pafmj.v1i1.7932

This is an Open Access article distributed under the terms of the Creative Commons Attribution License (https://creativecommons.org/licenses/by-nc/4.0/), which permits unrestricted use, distribution, and reproduction in any medium, provided the original work is properly cited.

\section{INTRODUCTION}

Nose is the vital organ of thehuman body, playing important role in warming, humidifying and filtering inspired air before reaching the lungs. There are three paired projections from thelateral nasal wall called superior, middle and inferior turbinates. Inferior turbinate is a separate bone covered by mucosa. The normal size of inferior turbinate is $50-60 \mathrm{~mm}$ long, $7.5 \mathrm{~mm}$ high and $3.8 \mathrm{~mm}$ wide. Inferior turbinate size can be enlarged either due to anincrease in cell size called hypertrophy or increase in cell no called hyperplasia. Both the terms are used interchangeably. ${ }^{1}$ Turbinate hypertrophies can occurdue to increase in soft tissue mass, bone, or both. Inferior turbinate hypertrophy (ITH) may be associated with Deviated Nasal Septum (DNS) or may exist in isolation. Inferior turbinate hypertrophy causing nasal obstruction affects approximately $10-20 \%$ adult population. ITH may occur due to various clinical conditions such as allergic rhinitis, vasomotor rhinitis, and other iatrogenic rhinopathies. Hypertrophy of Inferior Turbinate (IT) may occur as

Correspondence: Dr Fazal I Wahid, Medical Teaching Institute, Lady Reading Hospital, Peshawar Pakistan compensatory phenomenon due to the cseptal deviation to opposite side. ${ }^{2,3}$ ITH may present as nasal obstruction, difficulty in breathing, headache and facial discomfort. ITH causes decreased airflow through sinuses leading to sinusitis and subsequent complications. The aim of treatment of ITH is to reduce its size and ensure adequate air passage through nasal cavities. ${ }^{4}$ The size of enlarged inferior turbinate can be reduced with the help of medicines or surgical techniques. Amongst the medicine include topical corticosteroid nasal spray, anti-histamines, sympathomimetic agents and anticholinergic drugs. Sometime medical therapy is not sufficient to reduce soft tissue bulk of hypertrophied turbinate to obtain required results, soft tissue mass, bone or both can be reduced by various techniques. ${ }^{2}$ Surgical procedures usedby numerous otolaryngologists around the globe include partial or total turbinectomy, turbinoplasty, submucous diathermy, radio frequency ablation, laser-assisted ablation, cryotherapy and ultrasonic reduction. The prime purpose of all these surgical techniques is to reduce the anatomical mass of the turbinate on one hand while maintaining physiological function of turbinate on other hand. ${ }^{5}$ 
Multiple surgical techniques are exercised by different surgeons as there is no standardized technique until now due to its associated adverse effects like bleeding, crusting, dryness, adhesion, hyposmia, and bone necrosis. ${ }^{6}$

Keeping in view the trauma of surgery and its associated adverse events, this studyaims to compare outcome of medical therapy with surgery for ITH in a tertiary care hospital, where it is the first research work of its nature.

\section{METHODOLOGY}

This prospective comparative study was conducted at the Department of Ear, Nose, Throat, Head and Neck Surgery, Medical Teaching Institute, Lady Reading Hospital, Pakistan, fromJanuary to December 2019. To test the hypothesis, the sample size was calculated using an online sample size calculator (OpenEpi: Sample size for X-Sectional, Cohort, and Clinical Trials, taking confidence interval of $95 \%$ and the margin of error of 5\% https://www.openepi.com/Menu/OEMenu.htm.).7Power analysis revealed that 43 patients were required for each group with atotal sample size of 86 patients. These patients were divided into two equal groups. Patients in group A were subjected to medical therapy, while in group B, outfracture of hypertrophied inferior turbinated was conducted. A convenient (non-probability) sampling technique was adopted.

Inclusion Criteria: All patients of both genders in the age range from 15-50 years.

Exclusion Criteria: Patients having ITH with DNS, patients with ahistory of previous ITH surgery, patients, who were not willing for study, patients having other rhinopathies beside ITH.

Well informed written consent was taken from all patients explaining details of the study. Patients fulfilling inclusion criteria were meticulously evaluated in terms of details history, thorough examination and relevant investigations. All the patients whether treated medically or surgically were dealt by author only. Patients were interrogated regarding nasal obstruction, dyspnea, headache and other otorhinolaryngological and systemic illness, and any previous medical and surgical intervention. Thorough otorhinolaryngological and systemic examination was carried out focusing on the nose and paranasal status. Relevant biochemical investigations along with $x$-ray paranasal sinuses and CT paranasal sinuses where needed, were performed. Nasal obstruction due to ITH was assessed pre- and post-treatment by using $100 \mathrm{~mm}$ standardized Visual Analogue Scale (VAS). VAS was categorized in No (VAS 1-3), Mild (VAS 4-7) and Severe (VAS 8-10) nasal obstruction. Patients in group A were put on oral antibiotic Amoxicillin Clavulanate (Augmentin) $30 \mathrm{mg} /$ $\mathrm{kg}$ /day in 12 hourly divided doses, Oral antihistamine Loratadine (Tab Lorin NSA 10mg) once daily and corticosteroid (Fluticasone Propionate) nasal spray (Flexosone $50 \mathrm{mcg} 7.5 \mathrm{ml}$ ) 2 puffs twice a day. Medical treatment was given for a period of minimum 10 days. Nasal Obstruction was assessed using VAS before medical treatment, on $10^{\text {th }}$ day and $30^{\text {th }}$ day of treatment. Patients in group B were subjected to outfracture of IT. After admission, the patients were properly evaluated by Anesthetist one day before surgery for general anesthesia. On theday of sugary nose was packed with ribbon gauze soaked in $4 \%$ xylocaine with adrenaline in aseptic environment. Then after intubation under general anesthesia in a supine position patient was draped aseptically. Nose was properly examined using head light. Hypertrophied inferior turbinate was initially fractured medially and superiorly and then with the help of appropriate instrument it was displaced laterally. Thus, ensuring sufficient airway, then nose was splinted and then packed with medicated ribbon gauze. The patient was shifted to ENT ward after uneventful recovery from anesthesia. All patients were put on oral antibiotics, analgesics and antihistamine and vasoconstrictor nasal spray. Anterior nasal pack was removed after 24 hour and patient was discharged with post-operative instructions and for follow-up visits on 10 and 30 days of surgery. Nasal obstruction was assessed before surgery and on $10^{\text {th }}$ and $30^{\text {th }}$ day of surgery. All the collected data were recorded on a specially designed proforma and analyzed using SPSS25 . Quantitative data were presented as means $\pm S D$, while qualitative data were presented as frequency and percentage. Chi-square test was used to look for statistical significance of the results in both groups and $p<0.05$ was considered significant.

\section{RESULTS}

This study comprised of total 86 patients, in age range $15-55$ years with mean \pm SD age $33.47 \pm 9.57$ years. Males were $47(54.7 \%)$ and females were 39 (45.3\%) with male to female ratio of 1.2: 1 . Inthe group A males were $22(25.25 \%)$, females were $21(24.41 \%)$, while in group B males were $25(29.1 \%)$ and females were $18(20.3 \%)$. The commonest complaint of patients was bilateral nasal obstruction in $35(40.69 \%)$ patients inthe medically treated group and in $37(43.02 \%)$ 
patients inthe surgically treated group. Among unilateral nasal obstruction right side nasal obstruction was found in $5(5.81 \%)$ patients in group A and in $4(4.65 \%)$ patients in group B, while left-side nasal obstruction was recorded in $4(4.65 \%)$ and in $2(2.32 \%)$ patients in group A and B respectively (Table-I). There was no statistically significant difference innasal patency between the two groups before treatment $(p=0.59)$ and after 10 days of treatment $(p=0.69)$. However, at the end of one month, there was astatistically significant difference in nasal patency between the medically treated and surgically treated groups of patients $(p=0.023)$ (Table-II).

Table-I: Frequency and Percentage of presentations of patients in both groups (n-86).

\begin{tabular}{|c|c|c|c|}
\hline \multicolumn{2}{|l|}{ Presentation } & $\begin{array}{c}\text { Group A } \\
(\mathrm{n}=43), \text { No }(\%)\end{array}$ & $\begin{array}{c}\text { Group B } \\
(\mathrm{n}=43), \text { No }(\%)\end{array}$ \\
\hline \multicolumn{2}{|c|}{ Bilateral Nasal Obstruction } & $35(40.69 \%)$ & $37(43.02 \%)$ \\
\hline \multirow{2}{*}{$\begin{array}{l}\text { Unilateral } \\
\text { Nasal } \\
\text { Obstruction }\end{array}$} & $\begin{array}{l}\text { Right-Sided } \\
\text { Nasal } \\
\text { Obstruction }\end{array}$ & $5(5.81 \%)$ & $4(4.65 \%)$ \\
\hline & $\begin{array}{l}\text { Left-Sided } \\
\text { Nasal } \\
\text { Obstruction }\end{array}$ & $4(4.65 \%)$ & $2(2.32 \%)$ \\
\hline \multicolumn{2}{|c|}{ Headache } & $14(16.27 \%)$ & $8(9.30 \%)$ \\
\hline \multicolumn{2}{|c|}{ Difficulty in breathing } & $10(11.62 \%)$ & $9(10.46)$ \\
\hline \multicolumn{2}{|c|}{ Facial Discomfort } & $8(9.30 \%)$ & $6(6.97 \%)$ \\
\hline \multicolumn{2}{|c|}{ Nasal Allergic symptom } & $11(12.79 \%)$ & $2(2.32 \%)$ \\
\hline
\end{tabular}

Table-II: Nasal Patency measured before treatment and at $\mathbf{1 0}$ and 30-days post-treatment in both groups.

\begin{tabular}{l|c|c|c}
\hline Nasal Patency & $\begin{array}{c}\text { Group A } \\
(\mathbf{n = 4 3})\end{array}$ & $\begin{array}{c}\text { Group B } \\
(\mathbf{n = 4 3})\end{array}$ & $\begin{array}{c}p- \\
\text { value }\end{array}$ \\
\hline $\begin{array}{l}\text { Pretreatment Nasal } \\
\text { Patency (Mean } \pm \text { SD) }\end{array}$ & $2.74 \pm 0.49$ & $2.93 \pm 0.33$ & 0.59 \\
\hline $\begin{array}{l}\text { Nasal Patency after } 10 \\
\text { Days (Mean } \pm \text { SD) }\end{array}$ & $1.86 \pm 0.55$ & $1.81 \pm 0.54$ & 0.69 \\
\hline $\begin{array}{l}\text { Nasal Patency after 30 } \\
\text { Days (Mean } \pm \text { SD) }\end{array}$ & $1.30 \pm 0.51$ & $1.09 \pm 0.29$ & 0.023 \\
\hline
\end{tabular}

\section{DISCUSSION:}

Nasal obstruction due to ITH is common otolalryngological complaint faced by general physician and otorhinolaryngologist. This is a challenging issue for both patients and treating clinician, due to thelack of standardized treatment protocols developed by otolaryngologist around the globe. Thus numerous medical and surgical therapies have been practiced by otolaryngologists. ${ }^{8}$ This study is also an effort to focus on medical treatment of the issue. In this study there was aslight predominance of male gender (male to male ratio of 1.2:1), Similarly male predominance are also reported in other studied both from Asian and western counties that could be explained either probably due to social norm of the society where females have less chance of getting outdoor consultation, or ITH may affect men more than women due to high chance of exposure to environmental hazards. ${ }^{9-11}$ The age of patients studied ranged $15-55$ years with mean age of $33.47 \pm 9.57$ years that is comparable with results of Chavanwho divided the patients in two groups and in one group patient mean age was 29.48 years while in other group mean age was 28.28 years. ${ }^{12}$ Similarly in a Turkish study mean age of the patients was $32.16 \pm$ 10.48 years (range $20-59$ years). ${ }^{13}$ The reason is that the $3^{\text {rd }}$ and $4^{\text {th }}$ decade is the most active time of life, one can be affected easily by environmental hazards and seeks asolution on apriority basis to eliminateany health issues.

The main complaint of ITH is nasal obstruction, that if untreated in time may causetheupper or lower respiratory tract infection. In thecurrent study, bilateral nasal obstruction was the commonest findings; in $35(40.69 \%)$ and, $37(43.02 \%)$ patients in group A and B, respectively. This is supported by other studies too. Nelson found in his work that nasal obstruction was the most bother some preoperative symptoms in all patient groups.78,14 Mokbel from Egypt also carried study on reduction of ITH with a simple technique and he reported that nasal obstruction was accounted in all patients $(100 \%) \cdot{ }^{15}$ Nasal obstruction was recorded in both groups before treatment and there was no statistically significant difference $(p>0.05)$, as reported by Kaymakci that pre-operative nasal obstruction frequency and severity scores were not different between the two groups $(p-0.97$ and $p=0.130) .{ }^{16}$ Likely Nelson conducted a study on the comparison of symptoms and quality of life before and after the reduction of the inferior turbinate hypertrophy by two techniques and observed that there was no statistically significant difference between the two technique before intervention $(p=0.05) .{ }^{14}$ Thus it is not necessary that before intervention any difference may be found in patients. So patients can be grouped accordingly and comparison can be performed. In this study one group was subjected to medical therapy solely while the second group was subjected to a surgical technique called outfracturing of inferior turbinate to see the difference between the two treatment modalities. After 10 days of both treatment modalities nasal patency was checked using standardized VAS, and no significant difference was noted between the two groups $(p=0.69)$, but at one month follow-up there was asignificant difference between the two treatment modalities $(p=0.023)$, thus it is sho- 
wed from this study that surgery is abetter option for reducing the size of hypertrophied inferior turbinate. This observation agreeswith results of Mokbel who performed a comparative study for thereduction of ITH and noted that preoperative mean symptom score was $7.90 \pm 5.50$, while thepostoperative mean symptom score was $1.50 \pm 1.70$ with statistically significant improvement of symptom of nasal obstruction $(p<0.05) .{ }^{15}$ Similarly Unsal conducted a study on the reduction of ITH and its effect on the nose volume and found that the total volume of nose increased significantly after the treatment of ITH $(p<0.001) .{ }^{13}$ This study is also in consistence with Kaymakci's result who reported that both frequency and severity of nasal obstruction were significantly reduced after the reduction of the size of the inferior turbinate with radiofrequency and lateral displacement $(p<0.001) .{ }^{16-18}$

\section{ACKNOWLEDGMENT}

We acknowledge the work of Dr. Tariq P.G FCPS ENT in collection of data.

\section{IMITATION OF STUDY}

Limitation of this study is a short follow-up, so other studies with large sample size and long follow up may be conducted for long-term results.

\section{CONCLUSION}

Although there was no difference between the medical and surgical treatment modalities for the reduction of hypertrophied inferior turbinate at 10 days follow-up of treatment, however after one month surgical treatment was significantly effective than medical treatment.

\section{Conflict of Interest: None.}

\section{Authors' Contribution}

HR: Conceived the manuscrpt, FW: Collcted the data, BZ: Analyzed the data and draft the manuscipt, MJ: Critically reviwed the manuscript, NUH: Proof reading

\section{REFERENCES}

1. Aboulwafa WH, Kamal Saad AK, Abbas AY, Elewa MA, Eldahshan TAE. comparative study between submucosal diathermy and endoscopic partial turbinectomy in hypertrophied inferior turbinate. Egyp J Hospital Med 2019; 74 (4): 809-819.

2. Sabaa MA, Haitham M, El-Essawya M, Mohammed A, Azooza K. Endoscopic score: a new method for evaluating different inferior turbinate reduction techniques. Pan Arab J Rhinol 2020; 10(1): 27-33.

3. Giacomini PG, Passali FM, Flora B, Rosati V, Girolamo SD. Short term subjective outcomes of lateral fracture as a complementary treatment of coblation turbinoplasty in traumatized nose. Arch Otolaryngol Rhinol 2019 5(1): 26-30.

4. Yaseen ET, Khalaf AQ, Taher FS, Kareem AH, Al Hilali AMS. Surgical ultrasound reduction of inferior turbinate hypertrophy. J Otolaryngol ENT Res 2017; 8(3): 00247.

5. Vukoje N, Cvetinov M, Garito J. Utility of submucosal turbinoplasty for the treatment of chronic nasal obstruction. Glob J Oto 2017; 11(2): 555809.

6. Saulescu M, Sarafoleanu C. Surgery for nasal obstruction in inferior turbinate Hypertrophy. Roman J Rhinol 2015; 5(17): 25-30.

7. Dean AG, Sullivan KM, Soe MM. OpenEpi: Open Source Epidemiologic Statistics for Public Health, Version. www. OpenEpi.com, updated 2013, [Internet] Available from: (https:/ / www.openepi.com/Menu/OE_Menu.htm).

8. Riaz N, Manzoor T, Ali M. Comparison of nasal patency following submucosal resection of inferior turbinate and total inferior turbinectomy. Pak Armed Forces Med J 2012; 62(2): 160-163.

9. Sharma S. Importance of Treating Compensatory Hypertrophy of Inferior Turbinate in Cases of Septal Deviation Causing Nasal Obstruction. J Otolaryngol ENT Res 2016; 4(3): 00097.

10. Choi JH, Lee JK, Cho SH. Inferior Turbinate Surgery in SleepDisordered Breathing Patients with Nasal Obstruction: Principles and Various Techniques. Sleep Med Res 2018; 9(1):20-25.

11. Jourdy D. Inferior turbinate reduction. Operative Techniques in Otolaryngol 2014; 25(2): 160-170.

12. Chavan SS, Khond AD, Saple P, Kurle VR. Comparative study between diathermy and microdebrider for inferior turbinate reduction surgeries. Rhinol Online 2020; 13(1): 1-7.

13. Unsal O, Ozkahraman M, Ozkarafakili MA, Akpinar M, Korkut AY, Kurt Dizdar S, et al. Does the reduction ofinferior turbinate affect lower airway functions? Braz J Otorhinolaryngol 2019; 85(1): 43-49.

14. Nilsen AH, Helvik AS, Thorstensen WM, Bugten V. A comparison of symptoms and quality of life before and after nasal septoplasty and radiofrequency therapy of the inferior turbinate. BMC Ear, Nose Throat Disord 2018; 18(2): 2-10.

15. Mokbel KM. Inferior turbinate reduction by simple and nonexpensive technique. J OtorhinolHead Neck Surg 2020; 1(1):1002.

16. Kaymakci M, Gur OE, Ozdem C. Nasal obstruction: comparison of radiofrequency with lateral displacement of the inferior turbinate and radiofrequency alone. JPak Med Assoc2014; 64(1): 36-40.

17. Shamanna K, Godse A. Comparative study on outcome of septoplasty with or without turbinoplasty based on NOSE score. Res Otolaryngol 2018; 7(3):55-59.

18. Al Jabr IK, Alaboud N, Al Habeeb FA. Comparison of different surgical treatment modalities for nasal obstruction caused by inferior turbinate hypertrophy, Saudi J. Otorhinolaryngol Head Neck Surg 2021; 23(1): 11-15. 